\title{
"NÓS E OS ÍNDICES" - UM OUTRO OLHAR SOBRE A PRESSÃO INSTITUCIONAL POR PUBLICAÇÃO
}

\author{
Alexandre Reis Rosa \\ ESPM
}

Existem posições antagônicas quando o assunto é o sistema de pontos estabelecido pela CAPES como critério para avaliação (e ranking) dos programas de pós-graduação e do Currículo Lattes de pesquisadores no país. De um lado, há os que são a favor do sistema sob o argumento de estimular a produção e delimitar parâmetros objetivos de avaliação dessa produção. De outro, há aqueles que assumem o referido sistema como um grande equívoco da área acadêmica, pois corrompe o princípio da livre reflexão e pressiona os pesquisadores a divulgar resultados preliminares de pesquisa, quando não incompletos. Em meio ao debate, há também posições intermediárias que buscam avaliar os vícios e virtudes do sistema, como é a do professor Pedro Lincoln (Pensata RAE, v. 48, n. 2, p. 114-149, 2008), que aborda desde a dimensão estrutural até as conseqüências individuais do atual sistema, passando pelo crescimento da produção científica em Administração e pelo controle desses índices feito pelas comissões avaliadoras.

Todavia, sua pensata leva a entender que algumas questões, tais como o conhecido "publicar ou perecer", o fascínio pela quantificação e o "produtivismo", já foram suficientemente debatidas. Ele adota a posição de que "o Sistema de Avaliação da CAPES é um passo definitivo, e não dá para argumentar de maneira tal que a alternati- va à atual pressão por produção acadêmica fosse a supressão dos indicadores quantitativos do sistema ou mudança radical no Currículo Lattes" (p. 144, grifo meu). É como se o sistema existisse em algum lugar além do social, como algo auto-evidente e irreversível, fora do alcance do debate - e que sua principal virtude foi suprimir a "[...] acomodação ou desvio dos professores para outras atividades, não raro de interesse particular" (p. 145) -, como se hoje esses mesmos professores dedicassem seu tempo exclusivamente a atividades institucionais relacionadas à pesquisa.

Outro ponto do qual discordo são as exigências que se fazem para uma pesquisa ocupar um lugar na "Big Science", cuja "permissão" depende de nos submetermos aos padrões impostos pelos países centrais. Isso tem sido problematizado pela perspectiva pós-colonial que busca repensar essa assimetria a partir da periferia como forma de resistência ao que Souza Santos (2005) denomina "colonialidade do saber", capaz de delimitar desde o referencial teórico (em inglês, preferencialmente), até os temas mais relevantes a serem pesquisados.

No que diz respeito ao sistema de avaliação em si, há exagerada crença na sua "objetividade", cuja eficácia "nivela a enorme diversidade dos programas ao estruturar-se sob a óptica neutra do desempenho por números" (p. 146, grifo meu), nos moldes do Balanced Score Card (BSC), utilizado no meio empresarial. Aqui é como se toda pontuação atribuída aos canais de publicação (editoras, revistas e eventos) e, conseqüentemente, aos trabalhos publicados não tivesse sido feita por agentes social e politicamente situados.

Considerando a forma como esses pontos delimitaram o argumento do professor Lincoln, aparentemente, sua posição intermediária aproximase mais de uma defesa do sistema do que de uma resistência a ele; justifica sua lógica apontando mais virtudes que defeitos. Sendo assim, meu objetivo aqui é ressaltar os defeitos desse sistema, assumindo, portanto, o lado daqueles que resistem a essa lógica e que, de alguma forma, procuram olhar essa pressão institucional como um mecanismo de controle que visa normalizar programas e pesquisadores à atual política de produção científica instalada no país. Além disso, não podemos perder de vista que a própria dinâmica do sistema é um resultado das nossas práticas, que se relacionam aos acordos intersubjetivos, negociados e atualizados no cotidiano.

Tratarei, então, de assumir o contraditório e reposicionar a pressão institucional por publicação no centro do processo de aceleração da sociedade contemporânea, cujas conseqüências afetam o mundo acadêmico 
substituindo a reflexão pela reação, a imaginação pela descrição sociológica, a utopia pela realpolitik, transformando pensadores em burocratas que, em busca de maior produtividade, racionalizam o fazer acadêmico criando sistemas de gerenciamento muito próximos à lógica industrial, em que a economia de tempo é o ponto-chave do capitalismo moderno.

A relação entre tempo e produção nos remete a crítica marxista ao capitalismo industrial como modo de produção que se alimenta da velocidade. Quanto mais rápido o capital fosse transformado em lucro, mais rápido poderia ser reinvestido para gerar lucros ainda maiores. O advento da Revolução Industrial seria, portanto, o marco inicial para um mundo acelerado. Afinal, uma fábrica produzia mais bens em um dia de trabalho do que um artesão em toda sua vida.

No entanto, a aceleração da produção atinge seu ponto alto quando o engenheiro Frederick Wislow Taylor aciona seu cronômetro pela primeira vez em busca do "melhor" tempo para se executar uma tarefa. A lógica dos "tempos e movimentos" se espraia por diversos segmentos da sociedade, desencadeando um movimento sem precedentes de sobreposição entre tempo cronológico e tempo psicológico, levando-nos a viver uma sombria experiência intersubjetiva denominada pressa. Com efeito, o relógio se torna a ferramenta principal de gestão no cotidiano, regulando nosso tempo de trabalho, de estudo e de lazer, "tornando-nos escravos dos horários. [Pois] os horários representam prazos, e os prazos, por sua própria natureza, nos fazem correr" (HONORÉ, 2005, p. 33).

Essa relação com a métrica do tempo e a busca da eficiência que é imposta por um ritmo de vida acelerado sugere que podemos fazer mais em menos tempo. Logo, a produtividade tende a ser maior, gerando melhores resultados para quem consegue vencer os ponteiros do relógio. Temos com isso a criação de um antagonismo fundamental, que servirá de justificativa para os mecanismos de pressão institucional derivados dessa lógica: o "rápido" como sinônimo de normal, de produtivo, moderno e eficiente versus o "lento" como sinônimo de anormal, de improdutivo, atrasado e ineficiente. Quem não é capaz de seguir o movimento deve ser retirado de cena, pois gera gargalos na produção e compromete a produtividade.

Assim, nas palavras de Honoré (2005, p. 26, grifo meu), essa oposição se revela em modos de vida cuja percepção define que "depressa é agitado, controlador, agressivo, apressado, analítico, estressado, superficial, impaciente, ativo, quantidade-maisque-qualidade. Devagar é o oposto: calmo, cuidadoso, receptivo, tranqüilo, intuitivo, sereno, paciente, reflexivo, qualidade-mais-que-quantidade". Ou seja, temos quantidade e qualidade como fenômenos vinculados à velocidade com que conduzimos nossas práticas, entre as quais a produção de conhecimento científico.

Sendo assim, pensar na aceleração como um desdobramento da Revolução Industrial e do cronômetro taylorista nos leva a traçar um paralelo entre o espaço de produção fabril e o espaço de produção científica, ambos voltados à maximização da produção, devidamente mensurados por indicadores (como o BSC, por exemplo) que ajudam a controlar o fluxo, seja punindo os que não contribuem com os índices, seja recompensando os que adotam tempos e movimentos que alcancem a "melhor" forma de ampliar esses índices.

Esse perigoso paralelo entre empresa e academia foi problematizado por Waters (2006, p. 18), que diferencia esses dois mundos afirmando que "a vida acadêmica é um chamado, não um emprego. Daí a propensão das necessidades acadêmicas a se orientar para um mundo diferente daquele dominado pelo relógio de ponto". Com essa passagem, o autor destaca o que seria estar na academia e estar no mercado. Muito embora ele argumente que essa relação está bastante confusa nos últimos anos, defende que ainda é possível resistir à homogeneização dos dois mundos em face da hegemonia do mercado sobre a academia. Olhando a academia de Administração em particular, definida por Schwartzman (1991) como "híbrida" por abrigar simultaneamente o business e o scholar em seus gabinetes e salas de aula, podemos dizer que há uma predisposição genética de a nossa área sobrepor essas duas esferas. Além disso, quando a CAPES adota um sistema similar ao BSC como ferramenta de gerenciamento dos índices de publicação, percebemos que o modelo de quantificação preconizado reflete a busca de resultados, cuja maximização definirá quem receberá ou não recursos.

Nesse sentido, a lógica do "publicar ou perecer" começa a fazer sentido quando ser "veloz" implica assumir a quantidade como medida de todas as coisas em prejuízo da qualidade que advém de uma reflexão amadurecida, exaustivamente discutida, logo, "menos veloz". Pois, como argumenta Roesch (2003, p.166),

O trabalho científico é demorado. Entre um working paper e um artigo publicado em revista de reputação internacional, há no mínimo dois anos de trabalho. No Brasil, a impaciência impera sobre a disciplina e a reflexão na pesquisa. A coleta de dados, com freqüência, é assistemática. A análise é abreviada. Analisar, refletir e relatar leva muito tempo. E parece que não podemos 
perder tempo. [...] É necessário um tempo para voltar ao artigo e agregar-lhe valor. É exatamente este processo demorado que conduz à qualidade do texto final.

Ou seja, quando falamos em produção científica, devemos considerar o amadurecimento de uma idéia, que, de acordo com a associação feita por Honoré (2005) entre qualidade, quantidade e tempo de produção, precisa ocorrer "devagar" para ter qualidade.

Ao acelerar a produção, compromete-se a qualidade, e toneladas desses "fast papers" são despejadas em anais de congressos e congestionam revistas acadêmicas que, freqüentemente, demoram anos para responder a uma submissão. Olhando esse fenômeno como uma indústria, temos o desequilíbrio entre a velocidade da produção e a velocidade da distribuição, gerando um gargalo no sistema cuja solução requer alguma forma de gerenciamento que dê conta de gerar outputs tão pujantes quanto os inputs recebidos.

De partida, poderíamos pensar em duas soluções simples: aumentar os canais de publicação ou diminuir o número de submissões. A primeira estimularia a aceleração, ou seja, comprometeria a qualidade, uma vez que aumentaria as possibilidades de submeter mais artigos ainda. Já publicar menos poderia melhorar a qualidade na medida em os papers fossem mais bem incubados, porém isso colocaria o sistema em colapso, uma vez que a lógica da quantificação não aceita índices abaixo do permitido. Dessa forma, qualquer diminuição no número de artigos comprometeria o sistema de pontos, gerando um déficit institucional e pessoal para o grupo que estiver disposto a desacelerar. Com efeito, a lógica da quantidade se mantém, gerando um tipo de "produtivismo", pois os cientistas que não alcançarem os índices propostos, análogos aos do contexto empresarial, serão avaliados de forma negativa.

$\mathrm{Na}$ contramão, os pensadores preocupados em amadurecer sua reflexão e esperar o momento certo de divulgação são vistos com ressalvas e - não obstante sua enorme capacidade didática e intelectual - podem receber adjetivos do tipo "acomodados", "improdutivos", entre outros. Daí o fato de o termo "publicar ou perecer" não ser algo jocoso que não mereça nossa atenção, pois um pesquisador que não atingir sua "cota" de publicações pode ser afastado do programa, o que no setor privado pode ser sinônimo de demissão, dependendo do tipo de contrato firmado entre as partes. No setor público, sim, deixar de publicar é apenas uma questão simbólica, pois a estabilidade de emprego impede que ocorram demissões por isso.

Ora, se temos o BSC para mensurar nossa produtividade e, segundo a lógica do "publicar ou perecer", somos forçados a produzir no tempo "certo", então a academia está sendo regida, sim, pela lógica do cartão de ponto, cujos responsáveis são "aqueles que empregam as técnicas de administração de empresas e invadem a casa do intelecto, assim como os vendilhões invadiram o templo" (WATERS, 2006, p. 21). Desse modo, a possível solução para escoar a produção e manter os índices em alta seria a indústria de artigos criar uma série de práticas voltadas a resolver o problema dos índices.

Nesse contexto, emerge a figura do pesquisador-gerente, que, na impossibilidade de seguir o ritmo apenas com métodos tradicionais, começa a articular recursos de produção que devem se movimentar na velocidade "certa" para o sistema se reproduzir e não parar. Considerando especificamente a área de Administração, temos, de um lado, os pesquisadores que conseguem se dedicar exclusivamente à pesquisa, não obstante baixos salários e recursos muitas vezes escassos, e com alguma dificuldade conseguem seguir o ritmo. De outro, temos a emergência da figura emblemática do "fast researcher", ou seja, do pesquisador veloz, acelerado, capaz de, ao mesmo tempo, ser professor, consultor, orientador e ainda publicar dezenas de papers, não obstante sua própria (in)capacidade de pensar e refletir sobre todos eles.

Do ponto de vista histórico, a primeira mudança significativa que marcou a aceleração da produção acadêmica pode ser identificada com a redução no tempo de produção de uma tese de doutoramento. Poderíamos indagar: quanto tempo custa uma tese? Até 1998, a CAPES estabelecia e também financiava um estudante de doutorado no Brasil por um período de até 12 anos. Esse era o tempo que custava uma tese. Ou seja, prevalecia a lógica da reflexão "devagar", em que o tempo de duração da pesquisa era determinado pela envergadura da idéia a ser desenvolvida. Com efeito, o pesquisador podia se debruçar sobre o estado da arte, coletar dados em estudos longitudinais que permitiam captar o fenômeno com espaço de tempo razoável para verificar suas mudanças ao longo desse tempo e ainda voltar ao texto final diversas vezes, agregando críticas e melhorando-o. Nessa mesma direção, a produção de papers poderia seguir um ritmo similar, com artigos que poderiam ser maturados por meses e anos.

$\mathrm{Na}$ descrição acima, visualizamos um cenário quase idílico de produção cientifica em que o tempo psicológico não sofria a pressão do tempo cronológico, pois poucos doutorandos chegavam de fato aos 12 anos de tese. Evidentemente, isso não significa que antes tínhamos necessariamente trabalhos com mais qualidade do que hoje. A questão é que potencialmente isso poderia ser feito, já que o pesqui- 
sador sofria uma pressão menor para concluir a pesquisa. Após a mudança no tempo de defesa, chegou-se ao tempo limite de 48 meses, ou seja, três vezes menor que o anterior, e ainda atrelou-se esse tempo ao sistema de pontos contabilizados na avaliação dos programas. Assim, o sistema premia defesas rápidas e penaliza defesas lentas (acima de 48 meses para teses e 24 meses para dissertações). Assim, inicia-se a pressão do tempo cronológico. Pois, independentemente da proposta de tese, o tempo é o balizador, e a pesquisa deve se submeter ao prazo, sob o risco de perder pontos, logo, "perder" posições no ranking da CAPES. Por conseguinte, a produção de artigos começa também a entrar na contabilidade, sendo inclusive exigência para os recém-titulados: ou submetem um artigo da tese (dissertação) ou não recebem o título. Não querer publicar rápido deixa de ser uma opção...

Nesse contexto, desenha-se o cenário em que vivemos hoje. A CAPES cria o sistema Qualis, atribui pontos a cada canal de distribuição (publicação) e inicia a corrida por pontos, quanto mais melhor! A academia começa a se movimentar sob lógica industrial, e pesquisadores assumem o comando dos grupos de pesquisa como gerentes assumem o comando da equipes de produção. O tempo cada vez mais escasso - se torna um bem valioso, e o fast researcher começa a gerenciar eventos, publicações, projetos e orientações como rotinas organizacionais, em ritmo sem precedentes.

Nossos congressos, cada vez mais numerosos e suntuosos, são eventos de celebração do tempo. Com o crescente volume de trabalhos a serem "apresentados", o controle do tempo de apresentação passa a ser a principal função daqueles que coordenam as mesas. Antes tínhamos a chamada "apresentação tradicional", com 20 minutos por congressista. Agora temos um novo formato, a "apresentação interativa", com 10 minutos por congressista, ou seja, metade do tempo "tradicional". Isso possibilita uma ampliação do número de trabalhos a serem aceitos. Se essa lógica continuar a se reproduzir, chegaremos ao formato de cinco, três minutos, ou à anedótica situação de "conte seu artigo em 15 segundos"...

Quando observamos a evolução dos Enanpads ao longo dos seus mais de 30 anos (FACHIN, 2006), os números da última década chamam nossa atenção pelo crescimento acentuado das submissões. Contudo, não tivemos um crescimento equivalente de avaliadores, ou seja, temos mais trabalhos a serem avaliados por um número desproporcionalmente menor de pessoas para avaliar. Problema: sobrecarga de trabalho, 10, 15, 20 trabalhos para serem lidos em prazos pouco maiores do que um mês. Solução: ler rápido e dar a sentença o quanto antes, caso contrário o deadline será literalmente uma "linha de morte". Considerando o fator tempo como primordial para uma avaliação detalhada dos trabalhos, temos uma leitura apressada dos trabalhos submetidos, podendo ocorrer aprovações ou rejeições injustas de muitos deles.

Considerando que muitos pesquisadores brasileiros não se dedicam exclusivamente à pesquisa, essa sobrecarga acaba impactando as demais atividades docentes, como as aulas, a orientação de teses e dissertações, e a própria produção dos artigos desenvolvidos por esses docentes. Como o professor Lincoln destaca, por exemplo, cumprir os prazos de defesa das teses e dissertações torna-se difícil "[...] porque os maiores causadores do estouro de prazos são os próprios orientadores, de agendas sobrecarregadas" (p. 147).
Ora, retomando o paralelo entre academia e empresa, poderíamos perguntar: como um executivo de mercado resolveria esse problema? Uma alternativa seria trabalhar horas extras, sacrificando momentos de descanso e lazer, correndo o risco de assumir o quadro patológico de workaholic. Uma alternativa, mais eficaz no meio empresarial, seria descentralizar as atividades, delegando algumas delas à sua equipe e assumindo o papel de gestor desse fluxo de atividades. Com isso, os prazos são cumpridos e conseguem-se mais resultados com menos tempo. Na lógica capitalista, isso é produtividade!

No atual contexto acadêmico, ocorre uma espécie de benchmarking, que é gerido pela figura do fast researcher, que, em casos específicos, delega parte dos seus afazeres à sua equipe de produção, mestrandos e doutorandos devidamente selecionados em seus programas de pós-graduação. Nesse momento, ele consegue responder a todas as demandas que o afligem, equilibrando rapidamente demandas muito superiores ao que um pesquisador tradicional consegue realizar e, ao mesmo tempo, se fazendo presente (ou representado) na graduação, na pós-graduação, em palestras, nos congressos, nas comissões avaliadoras, nas consultorias, além de muitas vezes conseguir manter sua bolsa de produtividade.

Essas práticas de gestão podem ser incluídas no que o professor Lincoln define como "submundo na produção acadêmica turbinada que é difícil coibir diretamente, mas a cujas causas estruturais é preciso estar atento" (p. 149). Porém, vale ressaltar que essa atenção só poderá ser exercida quando essas práticas se tornarem objeto de debate, diferentemente do que ocorre na nossa área, em que isso é encarado em alguns casos como um tabu. Afinal, existem pesquisadores que se 
beneficiam delas, e para estes não há como cumprir todos os prazos assumidos se os seus doutorandos e mestrandos deixarem de dar aula no seu lugar, deixarem de avaliar os trabalhos sob sua responsabilidade ou até mesmo deixarem de escrever os artigos colocando-o como "co-autor".

A discussão dessas práticas passa pela questão ética. Pelo estabelecimento de parâmetros adequados à profissão de cientista em geral e à produção científica em particular. $\mathrm{Na}$ área de ciências da Saúde isso se tornou objeto de debate e regulamentação, com a criação de regras para produção e publicação de textos, que visam coibir essa gestão de equipes da forma como ocorre no submundo da produção turbinada. Um comitê formado por editores de revistas internacionais na área de Saúde criou o chamado "uniform requirements for manuscripts" (ICMJE, 2007), que, entre outras normalizações, estabelece os critérios para distinguir autores de outros colaboradores. O crédito de autor deve ser baseado em: (i) substanciais contribuições para a concepção e projeto do trabalho, obtenção de dados, ou análise e interpretação dos dados; (ii) elaboração do artigo ou revisão crítica importante para o conteúdo intelectual; e (iii) aprovação final da versão a ser publicada.

Assim, para ser considerado autor do trabalho, o pesquisador citado deve, necessariamente, satisfazer essas três condições. Por conseguinte, o comitê de editores ressalta que ações como obtenção de financiamento, coleta de dados e supervisão ou chefia de grupo de pesquisa não são fatores que tornam uma pessoa autora do trabalho. No melhor dos casos, essas pessoas podem ser consideradas "colaboradores" da pesquisa, com agradecimentos formalizados no artigo.

Entre esses colaboradores que merecem nosso agradecimento, podemos incluir os orientadores de dissertação ou tese? Com base nos critérios acima, sim. São colaboradores, pois não satisfazem as exigências para serem considerados autores. Porém, esses mesmos critérios são passíveis de interpretação diversa, e o que ocorre é que muitas vezes esses orientadores, que colaboram com os artigos, se transformam magicamente em autores por conta de um poder simbólico que configura as posições no campo acadêmico e, sobretudo, resulta de uma economia simbólica (e material) em que orientadores e orientandos participam de um mercado regido por ascendência, medo ou gratidão.

Nada contra produzir com orientadores. Afinal, a razão fundamental de existir essa relação reside na convergência de idéias, que é condição necessária para trabalhos coletivos. O que preocupa é o caráter dessa relação, o lado pernicioso desse mercado que se manifesta na pressão de alguns orientadores obrigando alunos a citarem seus nomes, sendo que algumas vezes nem sabem do que trata o artigo. Afinal, em muitos casos, os alunos dependem dos seus orientadores para receber cartas de recomendação, indicações para bolsa, participação em projetos e até colocações no mercado de trabalho. Um tipo de clientelismo se instala nesse lado da relação e acaba sustentando a lógica da produção científica rápida e descentralizada, permitindo que o fast researcher seja capaz de responder à pressão por publicação, atendendo as expectativas do sistema que vigia, pune e gratifica os agentes de acordo com a proximidade deles em relação às metas de "produtividade" estabelecidas institucionalmente.

Tomando-se o Sistema de Avaliação da CAPES como principal mecanismo de legitimação dos programas de pós-graduação no país, pode-se afirmar que há certa dependência desses programas em relação aos parâmetros estabelecidos pelo governo. Dessa forma, esse sistema assume papel fundamental no controle e manutenção da produção científica na medida em que estimula seu ritmo por meio de um regime de punições e recompensas. Considerando que a escala de classificação dos programas varia de 3 a 7 e a dos pesquisadores bolsistas de produtividade varia do nível 2 ao $1 \mathrm{~A}$, cujo ranking é dinâmico por causa do mérito e do demérito na contabilidade dos pontos, então a pressão institucional por publicação exerce o papel de controle disciplinar por meio das comissões avaliadoras, que garantem o ranking desses programas e pesquisadores de acordo com a "produtividade", milimetricamente mensurada com o apoio de ferramentas como o BSC, tendo como referência o Sistema Qualis.

Em outros termos, esse controle nos remete ao poder disciplinar (FOUCAULT, 1987), que busca normalizar os agentes, fazendo-os funcionar de acordo com a norma, punindo os desviantes e recompensando os normais. Nesse sentido, a disciplina pode ser vista como uma técnica, com a qual se visa moldar padrões de comportamento por meio de uma pedagogia voltada principalmente para a manipulação do corpo, tornando-o mais ou menos submisso, dócil e útil.

Nos cursos de pós-graduação, essa norma é transmitida aos alunos, que já são socializados de forma acelerada. Em outras épocas, o pesquisador publicava seu primeiro artigo muitas vezes após a defesa da dissertação ou tese. Atualmente, na área de Administração, isso ocorre desde a mais tenra fase, isto é, depois de cursada a primeira disciplina no mestrado ou doutorado, os professores já exigem um "paper" como trabalho final das disciplinas. Considerando um alu- 
no que cursa três disciplinas em um semestre, ele será obrigado a escrever três artigos em menos de seis meses! Para os que conseguem essa façanha, há a recompensa de um conceito " $\mathrm{A}$ " no final da disciplina, já para os que não conseguem... Nesse momento começam a operar as mirabolantes linhas de montagem, em que, nos moldes do taylorismo, cada aluno se encarrega de "fabricar" uma parte do artigo, e no final da produção "alguns deles sobreviverão" e serão acolhidos pelos professores, que, após algum (ou nenhum) retoque, entrarão como "coautores" desses artigos.

Esse poder disciplinar também se manifesta na organização e codificação desses corpos na rede de relações do campo acadêmico. O que facilita a identificação dos sujeitos a serem normalizados e vigiados. E tem suas linhas de força determinadas pela posição que os programas e pesquisadores ocupam nessa rede, qual seja, mais ou menos próximos do que seja normal ou anormal na atual política científica da CAPES. A Figura 1 resume os parâmetros desse continuum, mostrando o papel da pressão institucional por publicação como elemento indutor da movimentação na rede.

Nesse caso, a pressão por publicação atua no sentido de deslocar programas e pesquisadores para os parâmetros tidos como normais, que estão concentrados na lógica dos pontos, sobretudo advindos das publicações. Além da própria CAPES e do CNPq, outras instituições, como a Anpad, tendem a reafirmar tais sistemas de recompensa e punição por meio da acreditação de publicações e de seus autores (RODRIGUES, 2004). Com isso, o poder do atual sistema se capilariza no seio dos programas filiados e se reproduz por meio dos associados que buscam as recompensas de serem "normais". Evidentemente, atrelada a esse poder, existe a resistência que se traduz na recusa de ser governado segundo determinadas normas, levando-nos a pensar que, longe de ser definitivo, o atual sistema pode, sim, ser repensado, ressignificado e, por que não, extinto.

O esforço de pensar alternativas para minimizar os efeitos colaterais do sistema de avaliação da CAPES já vem sendo feito por pesquisadores de outras áreas. Por estarem atreladas à problematização apresentada nesta pensata, duas propostas em particular merecem destaque. A primeira versa sobre a contabilidade de pontos e o efeito "produtividade" na prática da produção cientifica (LUIZ, 2006). Basicamente essa proposta busca redistribuir a pontuação valorizando outras atividades exercidas pelos pesquisadores. Entre as quais, valorizar aulas ministradas, a participação em bancas externas (que mostram o prestígio do pesquisador na área), a ponderação da nota atribuída ao autor e ao co-autor de um artigo (não é razoável um pesquisador que aparece como co-autor de "X" trabalhos receber o mesmo número de pontos que um pesquisador primeiro autor dessa mesma quantidade de trabalhos;

Figura 1 - 0 papel da pressão institucional como indutor da "normalidade"

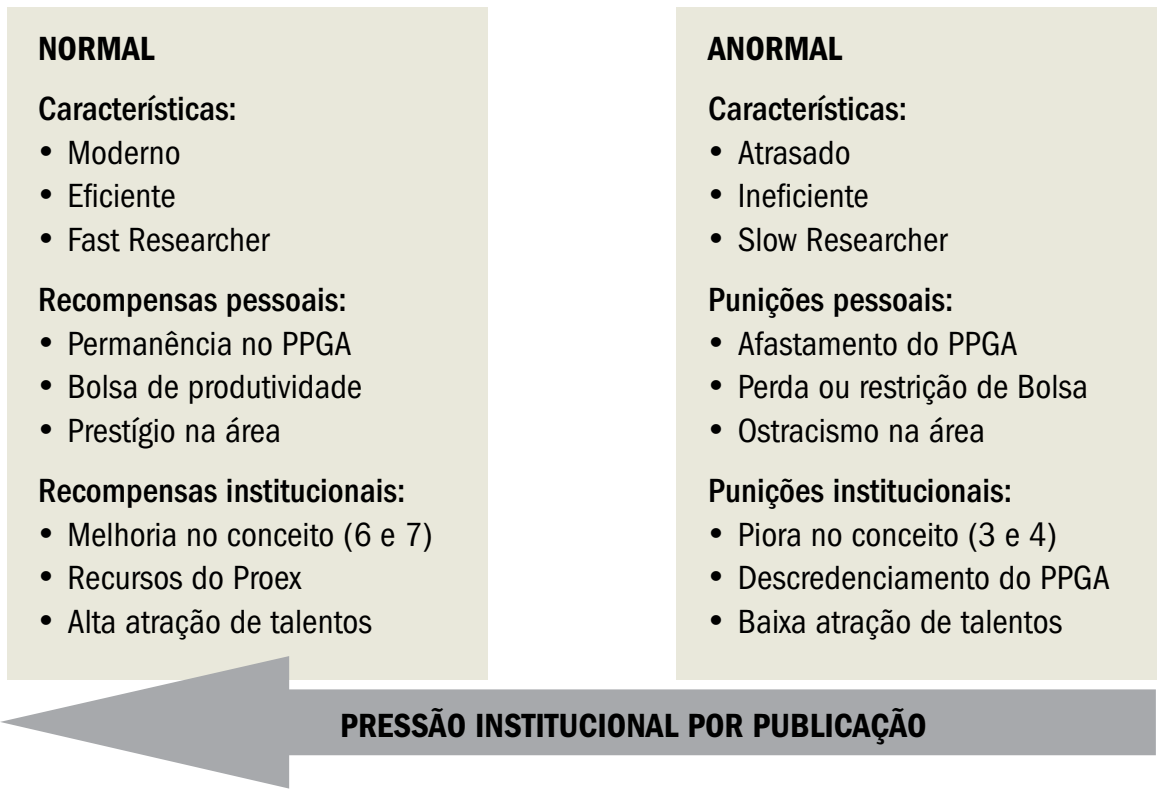


isso minimizaria o efeito orientadorautor), e, para os pesquisadores que mais contribuíram para área de conhecimento, atribuir pontos por cada citação feita pelos pares. Este último valorizaria os trabalhos de qualidade, ou seja, os que têm impacto na pesquisa, e ainda expressaria respeito e reconhecimento a esses pesquisadores (muitas vezes em estágio avançado da carreira), poupando-os da frenética corrida por pontos.

A segunda proposta versa sobre o tempo de defesa de teses e dissertações. Em recente pesquisa desenvolvida pela própria CAPES (SPAGNOLO e SOUZA, 2004) junto aos coordenadores de programas e membros das comissões avaliadoras, observou-se que há certo consenso no que diz respeito ao tempo de defesa de teses e dissertações como critério de pontuação. A idéia é flexibilizar esse tempo de acordo com as especificidades, dinâmicas e características de cada campo de conhecimento. Sendo que a variação de tempo estaria também apoiada no perfil de produção do aluno. Assim, o tempo de uma tese poderia ser medido não pelo tempo padrão, mas pela envergadura da proposta e pelo tema a ser explorado.

Sem a pretensão de concluir o tema no espaço de uma pensata, penso que o maior problema do paralelo entre produção fabril e produção científica reside no fator tempo. Produzir peças é diferente de produzir textos, pois estes últimos requerem amadurecimento, diálogo e revisão. Nesse sentido, não é equívoco algum pensar na incompatibilidade entre quantidade e qualidade na produção científica. Talvez o maior equívoco seja pensar que essas duas formas de produção possam ser comparadas e, pior, avaliadas com o mesmo instrumento (o BSC, por exemplo). Ainda que tenhamos sofisticados sistemas de informação que permitem processar grande quantidade de dados, a capacidade do pesquisador de interpretar e articular esses dados, artesanalmente como nos lembra Wright Mills (1972), se torna prejudicada ao ser feita com pressa. Olhar os números sem compreender a dimensão qualitativa que há por trás pode ser um caminho perigoso rumo à lógica da produção pela produção, apenas para atingir índices, pois disso nada fica, nada se aproveita. Os artigos tornam-se tão descartáveis quanto os produtos modernos. O relógio taylorista fez milagres na produção fabril, mas tem sido um problema a ser contornado na academia.

Um passo importante para rever essa lógica seria fazer o que melhor fazemos: pesquisar o problema. Afinal, como bem observa o professor Lincoln, "talvez ainda seja cedo para apresentar uma interpretação consistente dos fatos desse crescimento vertiginoso, e requer-se estudo formal" (p. 145). Estudos, sobretudo críticos, que façam contraponto à visão instrumental, que tende a ocultar desvios e ressaltar benefícios. O avanço para um estágio superior de avaliação depende fundamentalmente da crítica ao sistema.

Tendo eu aqui optado por assumir reflexão contrária ao sistema atual, muitos podem me apontar o dedo e acusar-me de certo dadaísmo ou de interpretação demasiadamente negativa e utópica. Na verdade, meu olhar sobre esse cenário é uma forma de resistência, uma tentativa de recuperar a magia de ser intelectual, de ouvir o sedutor chamado ao qual Waters (2006) se refere. Porém, essa postura diante da vida erudita tem sido cada vez mais difícil de assumir, pois o ritmo do nosso ofício tem-se travestido como o da fábrica, cujo barulho das máquinas nos ensurdece. Impedindo-nos de ouvi-lo. Para onde vamos? Não sei, só sei que precisamos ir devagar...

\section{REFERÊNCIAS}

FACHIN, R. Construindo uma associação científica: trinta anos da ANPAD. Porto Alegre: ANPAD, 2006

FOUCAULT, M. Vigiar e punir: o nascimento da prisão. Petrópolis: Vozes, 1987.

HONORÉ, C. Devagar: como um movimento mundial está desafiando o culto da velocidade. 2. ed. Rio de Janeiro: Record, 2005.

INTERNATIONAL COMMITTEE OF MEDICAL JOURNALS EDITORS (ICMJE). Uniform requirements for manuscripts submitted to biomedical journals. Updated October 2007. Disponível em: http://www.icmje.org/index.html. Acesso em 10.06.2008.

LUIZ, R. R. Avaliação de produtividade acadêmica: uma proposta de quantificação. Revista Brasileira de Pós-Graduação, v.3, n.6, p. 300-312, dez. 2006.

RODRIGUES, S. B. Réplica: Quem responde pelo desempenho limitado da produção científica em Administração no Brasil? Organização E Sociedade, v. 11, n. 29, jan./abr. 2004.

ROESCH, S. Quem responde pelo desempenho limitado da produção científica em Administração no Brasil? Organização \& Sociedade, v. 10, n. 28, p. 165-167, 2003.

SCHWARTZMAN, S. As ciências sociais nos anos 90. Revista Brasileira de Ciências Sociais, n. 16, p. 51-60, 1991.

SOUZA SANTOS, B. Para ampliar o cânone da ciência: a diversidade epistemológica do mundo. In: SOUZA SANTOS, B. (Org) Semear outras soluções: os caminhos da biodiversidade e dos conhecimentos. Rio de Janeiro: Civilização Brasileira, 2005.

SPAGNOLO, F; SOUZA, V. C. O que pode mudar na avaliação da CAPES? Revista Brasileira de PósGraduação, v. 1, n. 2, p. 8-34, nov. 2004.

WATERS, L. Os inimigos da verdade: eclipse da erudição e o fim da reflexão acadêmica. São Paulo: Unesp, 2006.

WRIGHT MILLS, C. A imaginação sociológica. 3. ed. Rio de Janeiro: Zahar, 1972. 